\title{
In vitro cytotoxicity and druglikeness of pyrazolines and pyridines bearing benzofuran moiety
}

\author{
Asma S. Al Wasidi ${ }^{1}$, Ashraf S. Hassan² ${ }^{*}$, Ahmed M. Naglah ${ }^{3,4}$ \\ ${ }^{1}$ Department of Chemistry, College of Science, Princess Nourah Bint Abdulrahman University, Riyadh 11671, Saudi Arabia. \\ ${ }^{2}$ Organometallic and Organometalloid Chemistry Department, National Research Centre, Cairo 12622, Egypt. \\ ${ }^{3}$ Department of Pharmaceutical Chemistry, Drug Exploration and Development Chair DEDC, College of Pharmacy, King Saud University, Riyadh 11451, \\ Saudi Arabia. \\ ${ }^{4}$ Peptide Chemistry Department, National Research Centre, 12622-Dokki, Cairo, Egypt.
}

\section{ARTICLE INFO \\ Received on: $12 / 12 / 2019$ \\ Accepted on: 27/02/2020 \\ Available online: 04/04/2020}

Key words:

Pyrazoline, pyridine,

benzofuran, cytotoxic activity,

druglikeness.

\begin{abstract}
A series of pyrazolines and pyridines bearing benzofuran moiety (M1-M10) were synthesized for evaluation of their in vitro cytotoxicity against MCF-7 and HepG2 cell lines. Furthermore, in silico drug-likeness study was carried out. The result of the cytotoxicity of M1-M10 showed that some compounds displayed cytotoxic activity against MCF-7 and HepG2 cells. An assessment of in silico drug-likeness study of M1-M10 illustrates that some compounds showed an agreement to the Lipinski, Ghose, Veber, Egan, and Muegge rules with orally bioavailable.
\end{abstract}

\section{INTRODUCTION}

Pyrazolines were known to exhibit various biological activities (Havrylyuk et al., 2016; Ozgun et al., 2019; Pandey et al., 2016). For example, $N$-acetyl pyrazoline (1), 1-(5-(4-bromophenyl)-3-(3,4,5-trimethoxyphenyl)-4,5-dihydro$1 H$-pyrazol-1-yl)ethanone, was selective and cytotoxic for leukemic cells (Stefanes et al., 2019). N-benzenesulfonamide pyrazoline (2), 4-(5-(4-methoxyphenyl)-1'-phenyl-3'-( $p$-tolyl)3,4-dihydro-1' $H, 2 H$-[3,4'-bipyrazol]-2-yl)benzenesulfonamide, acts as an antimalarial activity through the inhibition of $\beta$-hematin (Kumar et al., 2018). $N$-formyl-pyrazoline (3), 1-formyl-3phenyl-5-(4-isopropylphenyl)-2-pyrazoline, showed a promising antimicrobial activity (Sid et al., 2016).

Pyridines are important $N$-heterocyclic compounds due to their biological activities (Abdel-Galil et al., 2006;

\footnotetext{
*Corresponding Author

Ashraf S. Hassan, Organometallic and Organometalloid Chemistry

Department, National Research Centre, Cairo 12622, Egypt.

E-mail: ashraf_salmoon@yahoo.com
}

Klimešovă et al., 1999; Xu et al., 2017), such as compound (4), 1-(4-chloro-3-(trifluoromethyl)phenyl)-3-(6-(4-methoxyphenyl)2-methylpyridin-3-yl)urea, which displayed anticancer activities against NCI-USA cell lines (El-Naggar et al., 2018a). Furthermore, compound (5), ethyl 4-methyl-1,7,8,9-tetrahydropyrano[2,3-b] pyrrolo[2,3- $d$ ]pyridine-3-carboxylate, showed antibacterial activities against Escherichia coli and Staphylococcus aureus (Elkanzi et al., 2019).

Benzofuran moiety was very interesting $O$-heterocycle which was found in biologically active compounds (Atta et al., 2010; Wang et al., 2019; Zhu et al., 2013). Compound (6), 1-(7-allyl-6-hydroxy-4-methoxy-1-benzofuran-5-yl)-3-(4chlorophenyl)prop-2-en-1-one, exhibited an antiproliferative activity (Ragab et al., 2014). Compound (7), (4-hydroxy-3-methylphenyl) (2-(4-methoxyphenyl)-5-methylbenzofuran-3-yl)methanone, exhibited antibacterial activities (Jiang et al., 2011) (Figure 1).

In view of these above facts with the program for discovery biologically active compounds (Abd El-All et al., 2016; Elgemeie et al., 2008, 2009; Elgiushy et al., 2018; El-Naggar et al., 2018b; Hafez et al., 2013; Hassan and Hafez, 2018; Hassan et al., 2015a, 2015b, 2015c, 2016, 2017a, 2017b, 2017c, 2018a, 2018b, 
<smiles>COc1cc(C2=NN(C(C)=O)C(c3ccc(Br)cc3)C2)cc(OC)c1OC</smiles>

(1)

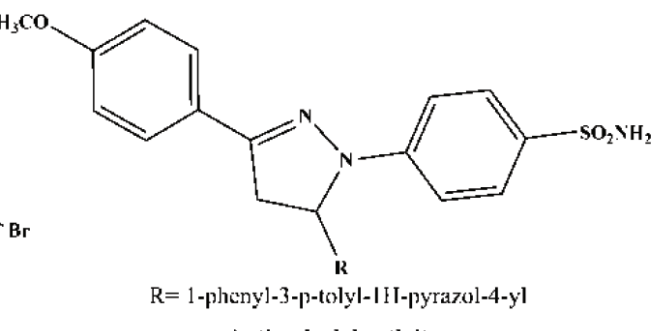

Antimalarial activity

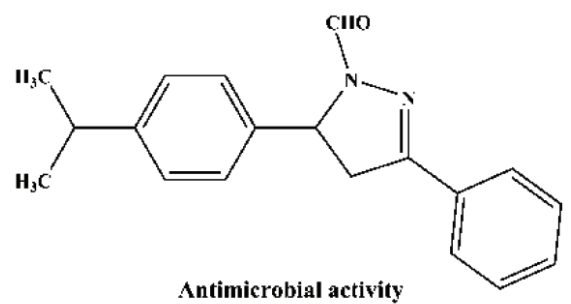

(3)<smiles>COc1ccc(-c2ccc(NC(=O)Nc3ccc(Cl)c(C(C)(C)C)c3)c(C)c2)cc1</smiles>

(4)<smiles>CCOC(=O)c1c[nH]c2c3c(cc(C)c12)OCCC3</smiles>
(5)<smiles>C=CCc1c(O)c(C(=O)/C=C/c2ccc(Cl)cc2)c(OC)c2ccoc12</smiles>

Antiproliferative activity

(6)

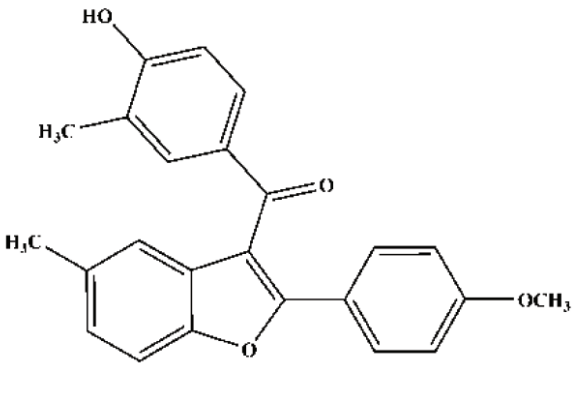

(7)

Figure 1. Examples of the bioactive compounds (pyrazolines, pyridines, and benzofurans).

2019; Khatab et al., 2019; Magd-El-Din et al., 2018; Osman et al., 2014), this research involves: (i) synthesization of pyrazolines and pyridines bearing benzofuran moiety (M1-M10), (ii) in vitro cytotoxicity evaluation of compounds M1-M10 against MCF-7 and HepG2 cell lines, and (iii) we performed in silico druglikeness of compounds M1-M10.

\section{MATERIALS AND METHODS}

\section{Chemistry}

The target compounds [1H-pyrazolines (M1-M3), $\mathrm{N}$-acetylpyrazolines (M4-M6), $\mathrm{N}$-phenylpyrazolines (M7 and M8), and pyridines (M9 and M10)] were synthesized according to the reported procedure (Osman et al., 2012).

\section{Cytotoxicity evaluation}

An in vitro cytotoxic activity $\left(\mathrm{IC}_{50} \mu \mathrm{g} / \mathrm{ml}\right)$ of pyrazolines (M1-M8) and pyridines (M9 and M10) against two cell lines (breast MCF-7 and liver HepG2) was measured by using the sulforhodamine B stain (SRB) assay (Skehan et al., 1990).

\section{Physicochemical properties and druglikeness}

The physicochemical properties and druglikeness of pyrazolines (M1-M8) and pyridines (M9 and M10) were predicted by using the SwissADME website (http://swissadme.ch).

\section{RESULTS AND DISCUSSION}

The chemistry

The synthetic route is outlined in Scheme 1. The target compounds [1H-pyrazolines (M1-M3), N-acetylpyrazolines (M4-M6), or $N$-phenylpyrazolines (M7 and M8)] were synthesized by the condensation of chalcones with hydrazine hydrate in ethanol, hydrazine hydrate in glacial acetic acid, or phenylhydrazine in ethanol, respectively. Furthermore, pyridines M9 and M10 were synthesized by the reaction of 3c with 2-cyano(thio)acetamide 4a, b (Osman et al., 2012).

\section{In vitro cytotoxic activity}

The cytotoxicity $\left(\mathrm{IC}_{50} \mu \mathrm{g} / \mathrm{ml}\right)$ of pyrazolines (M1-M8) and pyridines (M9 and M10) was measured by using the sulforhodamine B stain (SRB) assay (Skehan et al., 1990) against two cell lines (breast MCF-7 and liver HepG2). The result of the cytotoxicity values is shown in Table 1, and we could see that:

- The compounds, M1 ( $\left.\mathrm{IC}_{50}=12.08 \pm 1.20 \mu \mathrm{g} / \mathrm{ml}\right), \mathbf{M} 2\left(\mathrm{IC}_{5}\right.$ $\left.{ }_{0}=12.22 \pm 2.80 \mu \mathrm{g} / \mathrm{ml}\right), \mathbf{M 3}\left(\mathrm{IC}_{50}=10.43 \pm 1.12 \mu \mathrm{g} / \mathrm{ml}\right), \mathbf{M} 4$ $\left(\mathrm{IC}_{50}=10.65 \pm 4.61 \mu \mathrm{g} / \mathrm{ml}\right)$, and $\mathbf{M 6}\left(\mathrm{IC}_{50}=10.50 \pm 0.60\right.$ $\mu \mathrm{g} / \mathrm{ml}$ ), show cytotoxic activity against MCF-7 cancer cells, but this activity is less than the positive control [doxorubicin $\left.\left(\mathrm{IC}_{50}=4.70 \pm 0.55 \mu \mathrm{g} / \mathrm{ml}\right)\right]$. 


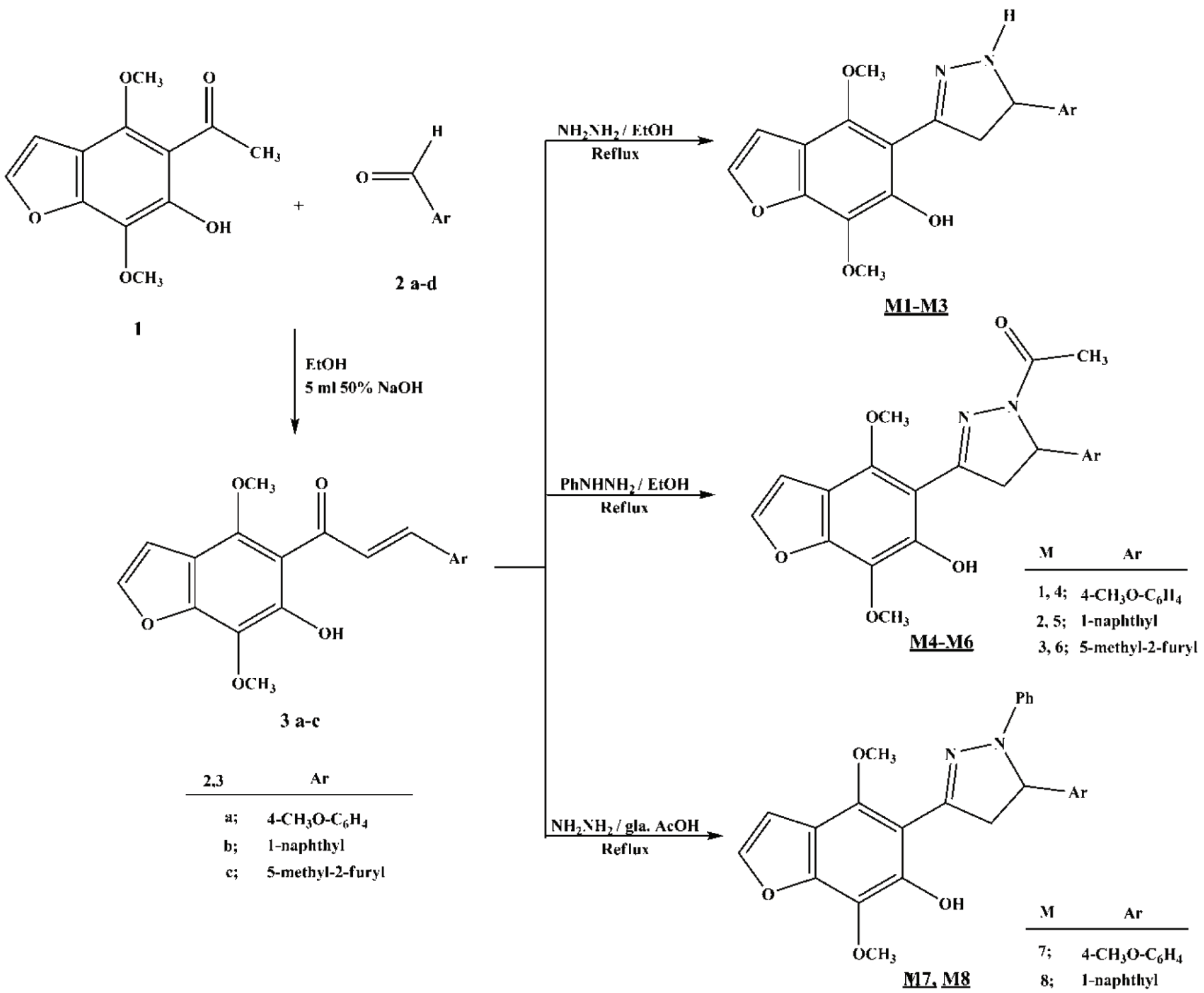<smiles>C=C(N)CC(=O)c1cc2c(OC)c(-c3cc([Tl])c(Cl)c([18OH])n3)c(O)c(OC)c2o1</smiles>

Scheme 1. Synthesis of pyrazolines (M1-M8) and pyridines (M9 and M10).

- For HepG-2 cancer cells, the compounds M1-M4 and M6 show $\mathrm{IC}_{50}$ values in the range from $10.41 \pm 2.71$ to $12.75 \pm$ $0.60 \mu \mathrm{g} / \mathrm{ml}$.

- The results revealed that the compounds M5 and M7-M10 did not exert any activity against MCF-7 and HepG-2 cancer cell lines.

\section{Physicochemical properties and druglikeness}

We predicted the physicochemical properties and druglikeness of the compounds (M1-M10) by using the SwissADME website (http://swissadme.ch).

The physicochemical properties give a global description of the structures of compounds (M1-M10) including molecular 
Table 1. In vitro cytotoxicity $\left(\mathrm{IC}_{50} \mu \mathrm{g} / \mathrm{ml}\right)$ of pyrazolines (M1-M8) and pyridines (M9 and M10).

\begin{tabular}{|c|c|c|c|c|}
\hline $\mathrm{OCH}_{31-}$ & $\prod_{-N}^{n}$ & & $\begin{array}{l}\mathrm{OCH}_{3} \\
\mathrm{M} 7, \mathrm{M8}\end{array}$ & $\mathrm{OH}_{\mathrm{OH}}$ \\
\hline Compounds & Ar & $\mathbf{x}$ & \multicolumn{2}{|c|}{ Human cancer cell lines } \\
\hline & & & MCF-7 & HepG2 \\
\hline M1 & 4- $\mathrm{CH}_{3} \mathrm{O}-\mathrm{C}_{6} \mathrm{H}_{4}$ & - & $12.08 \pm 1.20$ & $11.05 \pm 3.52$ \\
\hline M2 & 1-naphthyl & - & $12.22 \pm 2.80$ & $12.73 \pm 1.50$ \\
\hline M3 & 5-methyl-2-furyl & - & $10.43 \pm 1.12$ & $10.41 \pm 2.71$ \\
\hline M4 & $4-\mathrm{CH}_{3} \mathrm{O}-\mathrm{C}_{6} \mathrm{H}_{4}$ & - & $10.65 \pm 4.61$ & $12.75 \pm 0.60$ \\
\hline M5 & 1-naphthyl & - & NA & NA \\
\hline M6 & 5-methyl-2-furyl & - & $10.50 \pm 0.60$ & $11.25 \pm 5.65$ \\
\hline M7 & 4- $\mathrm{CH}_{3} \mathrm{O}-\mathrm{C}_{6} \mathrm{H}_{4}$ & - & NA & NA \\
\hline M8 & 1-naphthyl & - & NA & NA \\
\hline M9 & 5-methyl-2-furyl & $\mathrm{O}$ & NA & NA \\
\hline M10 & 5-methyl-2-furyl & S & NA & NA \\
\hline Doxorubicin & - & - & $4.70 \pm 0.55$ & $4.20 \pm 0.40$ \\
\hline
\end{tabular}

N.A. is no activity

Table 2. Physicochemical properties and lipophilicity of pyrazolines (M1-M8) and pyridines (M9 and M10).

\begin{tabular}{|c|c|c|c|c|c|c|c|c|c|c|c|}
\hline \multicolumn{2}{|l|}{ Properties } & M1 & M2 & M3 & M4 & M5 & M6 & M7 & M8 & M9 & M10 \\
\hline \multicolumn{2}{|c|}{ Molecular weight } & 368.38 & 388.42 & 342.35 & 410.42 & 430.45 & 384.38 & 444.48 & 464.51 & 392.36 & 408.43 \\
\hline \multicolumn{2}{|l|}{ \# Heavy atoms } & 27 & 29 & 25 & 30 & 32 & 28 & 33 & 35 & 29 & 29 \\
\hline \multicolumn{2}{|c|}{ \# Arom. heavy atoms } & 15 & 19 & 14 & 15 & 19 & 14 & 21 & 25 & 20 & 20 \\
\hline \multicolumn{2}{|l|}{ Fraction Csp3 } & 0.25 & 0.17 & 0.28 & 0.27 & 0.20 & 0.30 & 0.19 & 0.14 & 0.14 & 0.14 \\
\hline \multicolumn{2}{|c|}{ \# Rotatable bonds } & 5 & 4 & 4 & 6 & 5 & 5 & 6 & 5 & 4 & 4 \\
\hline \multicolumn{2}{|c|}{ \# H-Bond acceptors } & 6 & 5 & 6 & 7 & 6 & 7 & 6 & 5 & 8 & 7 \\
\hline \multicolumn{2}{|c|}{ \# H-Bond donors } & 2 & 2 & 2 & 1 & 1 & 1 & 1 & 1 & 2 & 1 \\
\hline \multicolumn{2}{|c|}{ Molar Refractivity } & 108.39 & 119.41 & 99.13 & 108.30 & 129.32 & 109.04 & 133.53 & 144.55 & 103.86 & 109.09 \\
\hline \multicolumn{2}{|c|}{ Total polar surface area $\AA^{2}$} & 85.45 & 76.22 & 89.36 & 93.73 & 84.50 & 97.64 & 76.66 & 67.43 & 121.88 & 140.45 \\
\hline \multirow{3}{*}{ Lipophilicity } & MLOGP & 1.21 & 2.22 & 0.52 & 1.20 & 2.17 & 0.53 & 2.54 & 3.50 & 0.06 & 0.44 \\
\hline & WLOGP & 2.52 & 3.66 & 2.41 & 2.78 & 3.92 & 2.67 & 4.43 & 5.58 & 4.36 & 4.95 \\
\hline & XLOGP3 & 3.29 & 4.57 & 2.82 & 2.66 & 3.94 & 2.19 & 4.98 & 6.26 & 3.88 & 3.83 \\
\hline
\end{tabular}

weight, molecular refractivity, topological polar surface area, number of rotatable bonds, heavy atoms, and hydrogen bond acceptors and donors (Table 2).

The bioavailability radar of the compounds, pyrazolines (M1-M8) and pyridines (M9 and M10), displayed a rapid evaluation of druglikeness.

The bioavailability radar includes the following six physicochemical properties:

(1) Lipophilicity (XLOGP3 between -0.7 and +5.0 ).

(2) Size (molecular weight between 150 and $500 \mathrm{~g} / \mathrm{mol}$ ).

(3) Polarity (the total polar surface area between 20 and $\left.130 \AA^{2}\right)$.

(4) Solubility ( $\log \mathrm{S}$ not higher than 6).

(5) Saturation (fraction Csp3 not less than 0.25).

(6) Flexibility (the number of rotatable bonds not more than 9).
The bioavailability radar of the compounds for six physicochemical properties is shown in Figure 2. The pink area represents the optimal range of these properties (Lovering et al., 2009; Ritchie et al., 2011), and the red line represents the properties of pyrazolines (M1-M8) and pyridines (M9 and M10).

In Figure 2, the red lines of four compounds (M1, M3, M4, and M6) are in the range of the pink area. Therefore, we can conclude that these compounds are predicted orally bioavailable.

Furthermore, druglikeness was established based on the physicochemical properties to find oral drug candidates (Daina et al., 2017). There are five different rule-based filters which are defined as follows:

1) Lipinski's filter includes molecular weight $\leq 500$, MLOGP (lipophilicity) $\leq 4.15$, hydrogen bond acceptors 

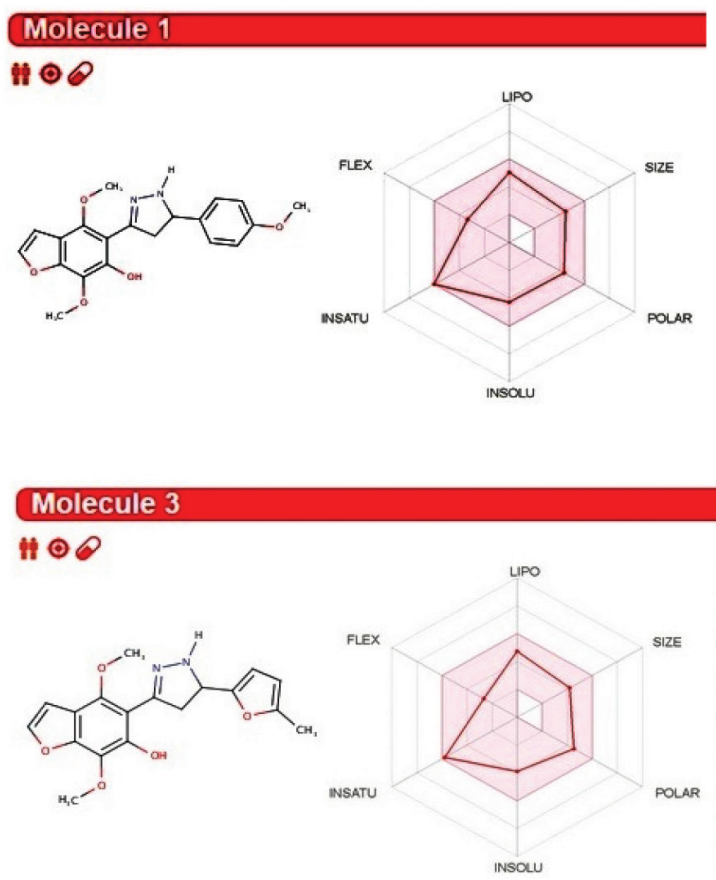

\section{Molecule 5}

100

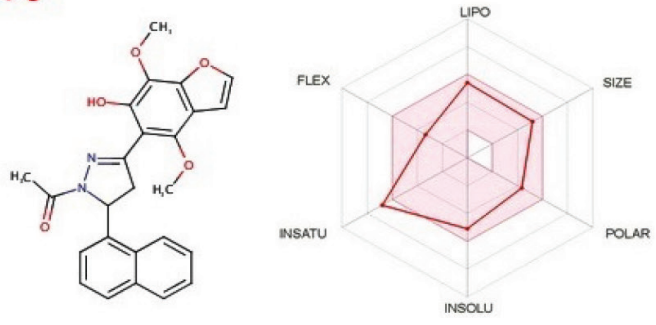

\section{Molecule 7}

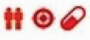

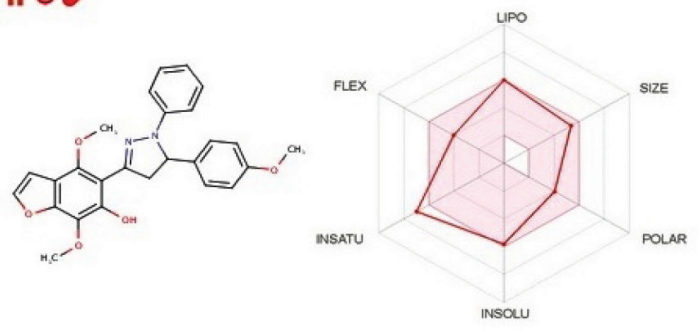

\section{Molecule 9}

100<smiles></smiles>

\section{Molecule 2}

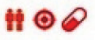
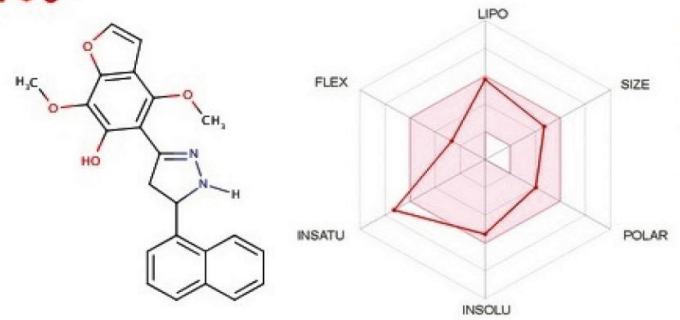

\section{Molecule 4}

\section{$1 \odot 0$}
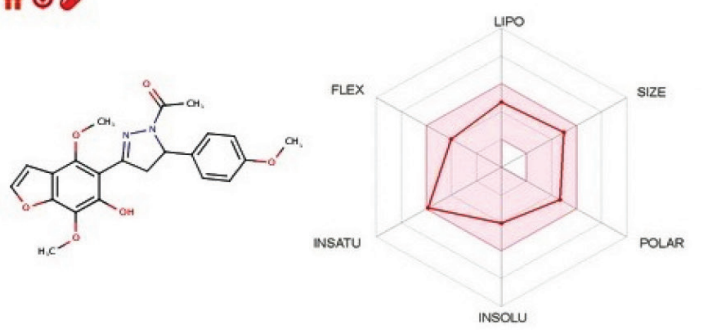

\section{Molecule 6}

100
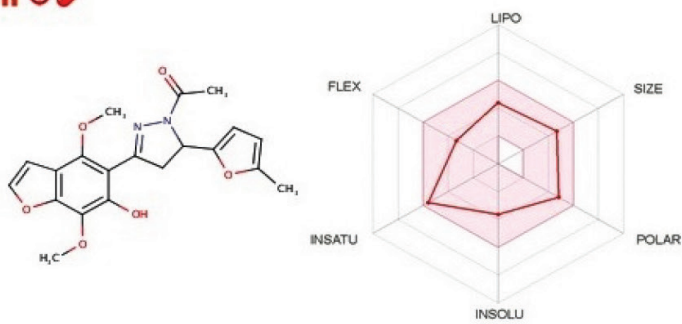

\section{Molecule 8}

i 00
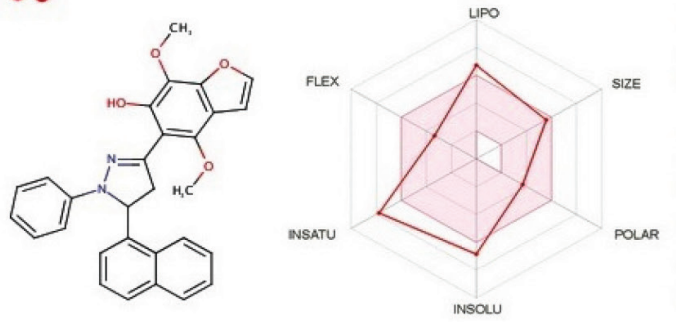

Molecule 10

100<smiles></smiles>

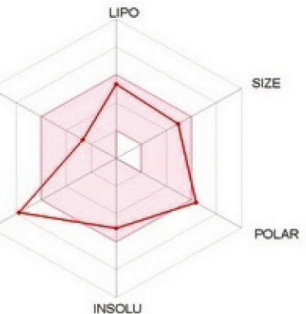

Figure 2. The bioavailability radar of pyrazolines (M1-M8) and pyridines (M9 and M10). 
Table 3. Drug-likeness evaluation of pyrazolines (M1-M8) and pyridines (M9 and M10).

\begin{tabular}{|c|c|c|c|c|c|c|c|c|c|c|}
\hline Rule-based filters & M1 & M2 & M3 & M4 & M5 & M6 & M7 & M8 & M9 & M10 \\
\hline Lipinski violations & Yes & Yes & Yes & Yes & Yes & Yes & Yes & Yes & Yes & Yes \\
\hline Ghose violations & Yes & Yes & Yes & Yes & Yes & Yes & $\begin{array}{l}\text { No; } 1 \text { violation: } \\
\text { MR > } 130\end{array}$ & $\begin{array}{l}\text { No; } 1 \text { violation: } \\
\text { MR > } 130\end{array}$ & Yes & Yes \\
\hline Veber violations & Yes & Yes & Yes & Yes & Yes & Yes & Yes & Yes & Yes & $\begin{array}{l}\text { No; } 1 \text { violation: } \\
\text { TPSA }>140\end{array}$ \\
\hline Egan violations & Yes & Yes & Yes & Yes & Yes & Yes & Yes & Yes & Yes & $\begin{array}{l}\text { No; } 1 \text { violation: } \\
\text { TPSA > } 131.6\end{array}$ \\
\hline Muegge violations & Yes & Yes & Yes & Yes & Yes & Yes & Yes & $\begin{array}{l}\text { No; } 1 \text { violation: } \\
\text { XLOGP } 3>5\end{array}$ & Yes & Yes \\
\hline
\end{tabular}

$\leq 10$, and hydrogen bond donors $\leq 5$ (Lipinski et al., 2001).

2) Ghose's filter includes $160 \leq$ molecular weight $\leq 480$, $-0.4 \leq$ WLOGP (lipophilicity) $\leq 5.6,40 \leq$ the molar refractivity $\leq 130$, and $20 \leq$ number of atoms $\leq 70$ (Ghose et al., 1999).

3) Veber's filter includes the number of rotatable bonds $\leq$ 10 and the total polar surface area $\leq 140$ (Veber et al., 2002).

4) Egan's filter includes WLOGP (Lipophilicity) $\leq 5.88$ and the total polar surface area $\leq 131.6$ (Egan et al., 2000).

5) Muegge's filter includes $200 \leq$ molecular weight $\leq 600$, $-2 \leq$ XLOGP3 (lipophilicity) $\leq 5$, the total polar surface area $\leq 150$, the number of rings $\leq 7$, the number of carbon $>4$, the number of heteroatoms $>1$, the number of rotatable bonds $\leq 15$, the hydrogen bond acceptors $\leq$ 10 , and the hydrogen bond donors $\leq 5$ (Muegge et al., 2001).

The result of drug-likeness evaluation of pyrazolines (M1-M8) and pyridines (M9 and M10) is shown in Table 3, and we can conclude that:

- All the compounds, pyrazolines (M1-M8) and pyridines (M9 and M10), are in agreement with the Lipinski's rule.

- According to Ghose's rule, all the compounds pass this rule excluding the two pyrazoline compounds (M7 and M8) due to the molar refractivity more than 130 .

- In the cases of Veber's rule and Egan's rule, all the compounds are in agreement with the two rules excluding one compound, pyridine M10, due to the total polar surface area more than 140 and 131.6, respectively.

- According to Muegge's rule, all the compounds are in agreement with this rule excluding pyrazoline M8 due to its lipophilicity (XLOGP3) more than 5.

\section{CONCLUSION}

In this work, a series of pyrazolines M1-M8 and pyridines M9 and M10 were synthesized for the evaluation of their in vitro cytotoxic activities against two cell lines such as MCF-7 and HepG2. In general, some of pyrazolines and pyridines displayed cytotoxicity. Furthermore, the drug-likeness study revealed that most of the compounds fulfill the requirements of Lipinski, Ghose, Veber, Egan, and Muegge rules, and four compounds (M1, M3, M4, and M6) are predicted orally bioavailable. These preliminary results provide the lead for the design of more potent and selective anticancer drugs.

\section{ACKNOWLEDGMENT}

This research was funded by the Deanship of Scientific Research at Princess Nourah Bint Abdulrahman University through the Fast-Track Research Funding Program.

\section{CONFLICT OF INTEREST}

The authors declare that they have no competing interests.

\section{REFERENCES}

Abd El-All AS, Hassan AS, Osman SA, Yosef HAA, Abdel-Hady WH, El-Hashash MA, Atta-Allah SR, Ali MM, El Rashedy AA. Synthesis, characterization and biological evaluation of new fused triazine derivatives based on 6-methyl-3-thioxo-1,2,4-triazin-5-one. Acta Pol Pharm 2016; 73:79.

Abdel-Galil EA, Mohamed AM, Mohamed SF, Abdel-Hafez NA, Hammam AEG. Anticancer activities of some newly synthesized pyridine, pyrane, and pyrimidine derivatives. Bioorg Med Chem 2006; 14:5481.

Atta SMS, Farrag DS, Sweed AMK, Abdel-Rahman AH Preparation of new polycyclic compounds derived from benzofurans and furochromones. An approach to novel 1,2,3-thia-, and selenadiazolofurochromones of anticipated antitumor activities. Eur J Med Chem 2010; 45:4920.

Daina A, Michielin O, Zoete V. SwissADME: a free web tool to evaluate pharmacokinetics, drug-likeness and medicinal chemistry friendliness of small molecules. Sci Rep 2017; 7:42717.

Egan WJ, Merz KM, Baldwin JJ. Prediction of drug absorption using multivariate statistics. J Med Chem 2000; 43:3867.

Elgemeie GH, Elsayed SH, Hassan AS. Design and synthesis of the first thiophene thioglycosides. Synth Commun 2009; 39:1781.

Elgemeie GH, Elsayed SH, Hassan AS. Direct route to a new class of acrylamide thioglycosides and their conversions to pyrazole derivatives. Synth Commun 2008; 38:2700.

Elgiushy HR, Hammad SF, Hassan AS, Aboutaleb N, Abouzid KAM. Acrylamide moiety, a valuable fragment in medicinal chemistry: insight into synthetic methodologies, chemical reactivity and spectrum of biological activities of acrylamide derivatives. J Adv Pharm Res 2018; $2: 221$

Elkanzi NAA, Bakr RB, Ghoneim AA. Design, synthesis, molecular modeling study, and antimicrobial activity of some novel pyrano[2,3-b]pyridine and pyrrolo[2,3-b]pyrano[2.3-d]pyridine derivatives. J Heterocyclic Chem 2019; 56:406.

El-Naggar M, Almahli H, Ibrahim HS, Eldehna WM, AbdelAziz HA. Pyridine-ureas as potential anticancer agents: synthesis and in vitro biological evaluation. Molecules 2018a; 23:1459.

El-Naggar M, Hassan AS, Awad HM, Mady MF. Design, synthesis and antitumor evaluation of novel pyrazolopyrimidines and pyrazoloquinazolines. Molecules 2018b; 23:1249.

Ghose AK, Viswanadhan VN, Wendoloski JJ. A knowledgebased approach in designing combinatorial or medicinal chemistry libraries for drug discovery. 1. A qualitative and quantitative characterization of known drug databases. J Comb Chem 1999; 1:55. 
Hafez TS, Osman SA, Yosef HAA, Abd El-All AS, Hassan AS, El-Sawy AA, Abdallah MM, Youns M. Synthesis, structural elucidation and in vitro antitumor activities of some pyrazolopyrimidines and Schiff bases derived from 5-amino-3-(arylamino)-1H-pyrazole-4-carboxamides. Sci Pharm 2013; 81:339.

Hassan AS, Askar AA, Nossier ES, Naglah AM, Moustafa GO, Al-Omar MA. Antibacterial evaluation, in silico characters and molecular docking of schiff bases derived from 5-aminopyrazoles. Molecules 2019; $24: 3130$.

Hassan AS, Awad HM, Magd-El-Din AA, Hafez TS. Synthesis and in vitro antitumor evaluation of novel Schiff bases. Med Chem Res 2018b; $27: 915$.

Hassan AS, Hafez TS, Ali MM, Khatab TK. Design, synthesis and cytotoxic activity of some new pyrazolines bearing benzofuran and pyrazole moieties. Res J Pharm Biol Chem Sci 2016; 7:417.

Hassan AS, Hafez TS, Osman SA, Ali MM. Synthesis and in vitro cytotoxic activity of novel pyrazolo[1,5-a]pyrimidines and related Schiff bases. Turk J Chem 2015a; 39:1102.

Hassan AS, Hafez TS, Osman SA. Synthesis, characterization, and cytotoxicity of some new 5-aminopyrazole and pyrazolo[1,5-a] pyrimidine derivatives. Sci Pharm 2015c; 83:27.

Hassan AS, Hafez TS. Antimicrobial activities of ferrocenyl complexes: a review. J App Pharm Sci 2018; 8:156.

Hassan AS, Mady MF, Awad HM, Hafez TS. Synthesis and antitumor activity of some new pyrazolo[1,5-a]pyrimidines. Chin Chem Lett 2017c; 28:388.

Hassan AS, Masoud DM, Sroor FM, Askar AA. Synthesis and biological evaluation of pyrazolo[1,5-a]pyrimidine-3-carboxamide as antimicrobial agents. Med Chem Res 2017b; 26:2909.

Hassan AS, Moustafa GO, Askar AA, Naglah AM, Al-Omar MA. Synthesis and antibacterial evaluation of fused pyrazoles and Schiff bases. Synth Commun 2018a; 48:2761

Hassan AS, Moustafa GO, Awad HM. Synthesis and in vitro anticancer activity of pyrazolo[1,5-a]pyrimidines and pyrazolo $[3,4-\mathrm{d}]$ [1,2,3]triazines. Synth Commun 2017a; 47:1963.

Hassan AS, Osman SA, Hafez TS. 5-Phenyl-2-furaldehyde: synthesis, reactions and biological activities. Egypt J Chem 2015b; 58:113.

Havrylyuk D, Roman O, Lesyk R. Synthetic approaches, structure activity relationship and biological applications for pharmacologically attractive pyrazole/pyrazoline-thiazolidine-based hybrids. Eur J Med Chem 2016; 113:145

Jiang X, Liu W, Zhang W, Jiang F, Gao Z, Zhuang H, Fu L. Synthesis and antimicrobial evaluation of new benzofuran derivatives. Eur J Med Chem 2011; 46:3526.

Khatab TK, Hassan AS, Hafez TS. V2O5/SiO2 as an efficient catalyst in the synthesis of 5-aminopyrazole derivatives under solvent free condition. Bull Chem Soc Ethiop 2019; 33:135.

Klimešovă V, Svoboda M, Waisser K, Pour M, Kaustovă J. New pyridine derivatives as potential antimicrobial agents. II Farmaco 1999; 54:666.

Kumar G, Tanwar O, Kumar J, Akhter M, Sharma S, Pillai CR, Alam MdM, Zama MS. Pyrazole-pyrazoline as promising novel antimalaria agents: a mechanistic study. Eur J Med Chem 2018; 149:139.

Lipinski CA, Lombardo F, Dominy BW, Feeney PJ. Experimental and computational approaches to estimate solubility in drug discovery and development settings. Adv Drug Deliv Rev 2001; 46:3.

Lovering F, Bikker J, Humblet C. Escape from Flatland: increasing saturation as an approach to improving clinical success. J Med Chem 2009; 52:6752.

Magd-El-Din AA, Mousa HA, Labib AA, Hassan AS, Abd ElAll AS, Ali MM, El-Rashedy AA, El-Desoky AH. Benzimidazole-Schiff bases and their complexes: synthesis, anticancer activity and molecular modeling as Aurora kinase inhibitor. Zeitschrift für Naturforschung C 2018; $73: 465$.
Muegge I, Heald SL, Brittelli D. Simple selection criteria for drug-like chemical matter. J Med Chem 2001; 44:1841.

Osman SA, Mousa HA, Yosef HAA, Hafez TS, El-Sawy AA, Abdallah MM, Hassan AS. Synthesis, characterization and cytotoxicity of mixed ligand Mn(II), Co(II) and Ni(II) complexes. J Serb Chem Soc 2014; 79:953.

Osman SA, Yosef HAA, Hafez TS, El-Sawy AA, Mousa HA, Hassan AS. Synthesis and antibacterial activity of some novel chalcones, pyrazoline and 3-cyanopyridine derivatives based on khellinone as well as $\mathrm{Ni}(\mathrm{II}), \mathrm{Co}(\mathrm{II})$ and Zn(II) complexes. Aust J Basic Appl Sci 2012; 6:852.

Ozgun DO, Gul HI, Yamali C, Sakagami H, Gulcin I, Sukuroglu M, Supuran CT. Synthesis and bioactivities of pyrazoline benzensulfonamides as carbonic anhydrase and acetylcholinesterase inhibitors with low cytotoxicity. Bioorg Chem, 2019; 84:511.

Pandey AK, Sharma S, Pandey M, Alam MM, Shaquiquzzaman M, Akhter M. 4,5-Dihydrooxazole-pyrazoline hybrids: Synthesis and their evaluation as potential antimalarial agents. Eur J Med Chem 2016; 123:476.

Ragab FA, Yahya TAA, El-Naa MM, Arafa RK. Design, synthesis and structure activity relationship of novel semisynthetic flavonoids as antiproliferative agents. Eur J Med Chem, 2014; 82:506.

Ritchie TJ, Ertl P, Lewis R. The graphical representation of ADME-related molecule properties for medicinal chemists. Drug Discov Today 2011; 16:65.

Sid A, Messai A, Parlak C, Kazancı N, Luneau D, Keşan G, Rhyman L, Alswaidan IA, Ramasami P. 1-Formyl-3-phenyl-5-(4isopropylphenyl)-2-pyrazoline: synthesis, characterization, antimicrobial activity and DFT studies. J Mol Struct 2016; 1121:46.

Skehan P, Storeng R, Scudiero D, Monks A, McMahon J, Vistica D, Warren JT, Bokesch H, Kenney S, Boyd MR. New colorimetric cytotoxicity assay for anticancer-drug screening. JNCI J Natl Cancer Inst 1990; 82:1107-12.

Stefanes NM, Toigo J, Maioral MF, Jacques AV, ChiaradiaDelatorre LD, Perondi DM, Ribeiro AAB, Bigolin Á, Pirath IMS, Duarte BF, Nunes RJ, Santos-Silva MC. Synthesis of novel pyrazoline derivatives and the evaluation of death mechanisms involved in their antileukemic activity. Bioorg Med Chem 2019; 27:375.

Veber DF, Johnson SR, Cheng H-Y, Smith BR, Ward KW, Kopple KD. Molecular properties that influence the oral bioavailability of drug candidates. J Med Chem 2002; 45:2615.

Wang B, Zhang Q, Luo J, Gan Z, Jiang W, Tang Q. One-step regioselective synthesis of benzofurans from phenols and $\alpha$-haloketones. Molecules 2019; 24:2187.

Xu F-Z, Wang Y-Y, Zhu Y-Y, Shao J-H, Yu G, Xue W, Wu J, Wu H-B, Shi J. Synthesis and biological activity of novel sulfone derivatives containing a $[1,2,4]$ triazolo[4,3-a]pyridine moiety. Phosphorus Sulfur Silicon Relat Elem 2017; 192:850

Zhu R, Wei J, Shi Z. Benzofuran synthesis via copper-mediated oxidative annulation of phenols and unactivated internal alkynes. Chem Sci 2013; 4: 3706.

\section{How to cite this article:}

Al Wasidi AS, Hassan AS, Naglah AM. In vitro cytotoxicity and druglikeness of pyrazolines and pyridines bearing benzofuran moiety. J Appl Pharm Sci, 2020; 10(04): $142-148$. 